\title{
Transatlantica
}

Revue d'études américaines. American Studies Journal

\section{Ira B. Nadel, ed. The Cambridge Companion to Ezra}

Pound.

Cambridge : Cambridge UP, 1999. 318p. \$19,95.

\section{Axel Nesme}

\section{OpenEdition}

\section{Journals}

Édition électronique

URL : http://journals.openedition.org/transatlantica/345

DOI : $10.4000 /$ transatlantica.345

ISSN : 1765-2766

Éditeur

AFEA

Référence électronique

Axel Nesme, «Ira B. Nadel, ed. The Cambridge Companion to Ezra Pound. », Transatlantica [En ligne], 1 | 2001, mis en ligne le 23 mars 2006, consulté le 29 avril 2021. URL : http://journals.openedition.org/ transatlantica/345; DOI : https://doi.org/10.4000/transatlantica.345

Ce document a été généré automatiquement le 29 avril 2021.

\section{c) (†) $\odot$}

Transatlantica - Revue d'études américaines est mis à disposition selon les termes de la licence Creative Commons Attribution - Pas d'Utilisation Commerciale - Pas de Modification 4.0 International. 


\title{
Ira B. Nadel, ed. The Cambridge Companion to Ezra Pound.
}

\author{
Cambridge : Cambridge UP, 1999. 318p. \$19,95.
}

\section{Axel Nesme}

1 Il s'agit ici, dans l'espace de 300 pages fort denses, de proposer au public une introduction à l'œuvre poundienne dans une perspective aussi bien littéraire, esthétique, philologique que politique et idéologique. L'ouvrage ne visant pas à esquisser un panorama des lectures critiques possibles, aucune orientation théorique n'est privilégiée.

2 L'article de G. Bornstein examine l'interaction entre Pound et Yeats, H.D., T.S. Eliot et James Joyce de 1908 à 1925, placée sous le signe de la coopération plus que de l'« angoisse de l'influence » théorisée par Harold Bloom. Bornstein expose la façon dont les échanges entretenus par Pound avec Yeats contribuent à accélérer la modernisation de ces deux écritures. Il souligne l'importance des rapports entre Pound et H.D. dans la définition de l'imagisme, et le rôle déterminant de Pound dans la composition de The Waste Land, dont la dette envers Pound se mesure à l'écart observable entre l'esthétique de la rupture que ce texte incarne, et les œuvres ultérieures de T.S. Eliot, plus discursives. Enfin l'article illustre le rôle actif que joua Pound dans la publication de Ulysses. Suivent quatre articles correspondant aux principales périodes de la créativité du poète. Le premier, signé par Hugh Witemeyer, assure un heureux équilibre entre description des leitmotifs de cette première période (mysticisme, néoplatonisme, idéalisation de la femme...) et définition des principes imagistes, puis vorticiste. Dans son évocation des Cantos I-XLI, Daniel Albright articule bien quant à lui les termes d'une poétique influencée par le Nô japonais (dans son rapport au temps et à l'espace) où la notion de voix (celle du poète ou de ses masques), occupe une place prépondérante, et d'une thématique (ainsi la désagrégation des voix dans les Cantos XII-XVI) permettant de dégager certains schèmes. Ces effets de récurrence ouvrent sur une nouvelle définition de la rime comme jeu d'écho entre thèmes et non simplement entre sonorités. Au sein de cette problématique, $\mathrm{D}$. Albright souligne la transition qui s'opère dans ces Cantos où à l'alternance des voix succède leur superposition. C'est aussi l'occasion pour le critique 
de rappeler que la fugue, dont le modèle est invoqué par Pound, est à appréhender non comme forme, mais comme texture. L'article s'achève au moment où, à partir des Cantos XXXI-XLI, le lien entre poésie et politique s'affirme, laissant la place à l'essai d'Ian Bell sur les Cantos XLII-LXXI, qui se trouve pour une large part contraint de montrer la cohérence d'un discours plus que d'une écriture. Cette difficulté se rencontre de nouveau, dans une certaine mesure, dans le texte de Ronald Bush sur les derniers Cantos, qui parcourt la thématique foisonnante de ces textes à travers les nombreuses hésitations dont ils témoignent. L'ouvrage se poursuit par une étude de Peter Nichols consacrée aux effets d'émulation et de résistance qui caractérisent l'impact des Cantos, étude qui donne lieu à un captivant parcours de la poésie américaine d'après-guerre. Par imitation ou par réaction, Ezra Pound en vient ici - quoique de façon parfois un peu systématique - à faire figure de père fondateur de la poésie de notre demi-siècle, jusqu'à la génération des $L=A=N=G=U=A=G=E$ poets qui valorisent la part d'indétermination que Pound chercha vainement à bannir de sa propre poésie. Après une étude de R. Taylor sur les difficultés posées par l'établissement du texte des Cantos (en raison de leurs révisions successives dues aussi bien à des tiers qu'à Ezra Pound lui-même), Massimo Bacigalupo nous propose un survol des écrits théoriques de Pound dans leurs rapports avec sa poésie, et Ming Xie examine dans le détail la pratique de Pound traducteur, privilégiant transposition et équivalences aux dépens du littéralisme, ce qui permet au critique d'avancer une vision des Cantos comme épopée de la traduction. La deuxième partie du livre se compose d'essais sur des sujets plus extra-littéraires. Ainsi, l'article sur Pound et les beaux arts nous montre le poète fasciné par le Quattrocento en tant qu'apogée du mécénat. Mais la bipartition qu'on vient de signaler, introduite par souci de clarté, n'implique aucune hiérarchie des priorités : de fait, l'essai consacré à Pound et à la musique poursuit le débat sur la pertinence du modèle de la fugue comme entrelacement de voix, appliqué à l'écriture poundienne : après avoir suggéré une parenté, notamment entre Pound et John Cage (car chez l'un comme chez l'autre, l'ordre sonore atteint un degré d'élaboration tel que l'oreille ne peut plus le distinguer du chaos) Michael Ingham conclut que l'ordre sous-jacent à ce chaos est justement celui de la voix. Après un article de Tim Redman qui examine les théories économiques aux fondements de l'idéologie des Cantos, l'essai de Helen M. Dennis, dans la lignée des gender studies, nous présente Pound prisonnier, dans ses rapports avec les femmes, des préjugés de son époque et des modèles de comportements hérités de ses lectures. L'idéalisation de la femme en muse ou en présence immanente dans la nature, d'abord dénoncée comme portant la marque d'un certain " phallogocentrisme », n'en est pas moins réhabilitée en fin d'article, lorsque la critique propose de lire dans cette exploitation de l'archétype féminin, non plus une façon de mythologiser la femme pour la réduire au silence, mais au contraire un effort pour la réinscrire dans l'ordre symbolique, contre les excès du discours victorien sur le corps féminin. L'ouvrage se termine par un article de Wendy Flory sur Pound et l'antisémitisme, indissociable, selon l'auteur, de la psychose paranoïaque qui s'installe chez Pound à partir de 1935 et qui s'exprime par la théorie du complot économique où Pound croit déceler l'origine des événements qui conduisent à la deuxième Guerre. La critique démontre de manière convaincante que les lectures, déconstructionnistes entre autres, visant à souligner la continuité entre l'écriture poundienne et l'idéologie antisémite du poète, voire entre modernisme et fascisme, occultent un peu trop commodément l'implication des majorités silencieuses sur lesquelles les études consacrées à l'holocauste mettent actuellement l'accent, pour 
conclure que le «calme » d'un Heidegger pendant la deuxième Guerre Mondiale était plus nocif que les divagations antisémites de Pound. Si à l'instar du volume de la même collection sur T.S. Eliot, l'on aurait aimé voir esquisser un état de la critique poundienne, ce Cambridge Companion n'en offre donc pas moins au lecteur les moyens de se repérer dans une œuvre monumentale et complexe et de dégager, jusque dans ses tiraillements, les termes de la poétique poundienne.

INDEX

Thèmes : Recensions

\section{AUTEUR}

AXEL NESME

Université Lumière-Lyon II 